\title{
Transformer Based AC Pulse Modulation System for Voltage Stabilization
}

\author{
Dr.habil.sc.ing. Ivars Rankis \\ Institute of IEEE \\ Riga Technical university \\ Riga, Latvia \\ rankis@eef.rtu.lv
}

\author{
M.sc.ing. Marcis Prieditis \\ Institute of IEEE \\ Riga Technical university \\ Riga, Latvia \\ marcis.prieditis@rtu.lv
}

\author{
M.sc.ing. Dmitry Shirkin \\ Institute of IEEE \\ Riga Technical university \\ Riga, Latvia \\ shirkini@inbox.lv
}

\begin{abstract}
In the paper some results of investigation of the singlephase transformer based AC pulse modulation mode regulated system of network voltage stabilization are presented. Switching processes in the device are regarded to application of transistor switches with proper snubbering circuits. Computer simulation as well experimental investigation of a model are done and its outcomes are presented.
\end{abstract}

Keywords- transformer; stabilization; bidirectional; switch; singlephase; calculation; simulation; snubber.

\section{INTRODUCTION}

A problem for developing of fast-operating simple and reliable AC single-phase voltage stabilizer is really actual one. It is connected with Internationally accepted standards which allow variations of AC supply voltage in range $+/-10 \%$ from the rated value $(230 \mathrm{~V}$ for the single-phase) of voltage level [1]. Thus electrical equipment is stressed by the higher meanings of voltage at the same time applying of higher voltages fosters in many applications rise of consumed power and decrease of efficiency. Therefore stabilization of the single phase $\mathrm{AC}$ voltage for customers is of high authority. Such stabilization devices must comply to some requirements - provide simplicity, cheapness, bi-directionality, to be reliable. Power ratings of stabilizers couldn't be above some $\mathrm{kW}$.

Such stabilizers can be developed on base of power electronic solutions - for instance it's possible to realize double-stage conversion - rectifying with succeeding invertation on necessary output voltage shape and parameters. But devices of such type shouldn't comply with requirements. It's proposed to use direct PWM controlled converting $[2,3,6]$ realizing bi-directional BUCK-BOOST operation on base of IGBT transistor application at application of the fastoperating sensors of the secondary voltage $[4,5]$. But anyway this solution is rather complex and asks for application of filtering devices [7] which rise as complexity as well cost of application.

In the last period have been proposed to apply systems where transformer is combined with semiconductor modulation tools $[9,10,11]$. Especially interesting is application of auto-transformers like devices which are characterizing with property when in case of small voltage variation range it's possible to gain-through load power which can be much larger as transformer rated power $[8,9,10]$. For instance in [9] it's shown that at $15 \%$ output voltage variation power of load could tenfold to be above one of an autotransformer's. Supplementing such device with controllable electronic switches it's possible to achieve stepwise change in small range a load voltage wave. At that simplest solution should be at application of only one secondary winding calculated for full load current and for BUCK case - contrary introduced regard to the separated by current ways the primary winding $[9,10]$.

The task of this paper is more deeply investigate operation regimes of the such device - transformer based AC modulation system.

\section{SCHEME OF THE DEVICE AND OPERATION PRINCIPLES}

Let's observe voltage regulation circuit which includes 2winding transformer and 2 regulation transistors (Fig.1). For simplicity reasons in Fig. 1 transistors are substituted with switches - S1, S2. Circuit is meant to compensate small range (up to $10 \%$ ) voltage deviations above the rated one in network on constant impedance load which consists from resistor $\mathrm{R}$ and inductance $\mathrm{L}$.

System works in following way: when load voltage is higher than needed, switch S2 is turned on (S1 off) and it connects the load to secondary winding $w_{2}$, which is connected in respect to primary winding $w_{l}$ in opposite phase. Primary winding $w_{l}$ is constantly connected to supply voltage of the circuit.

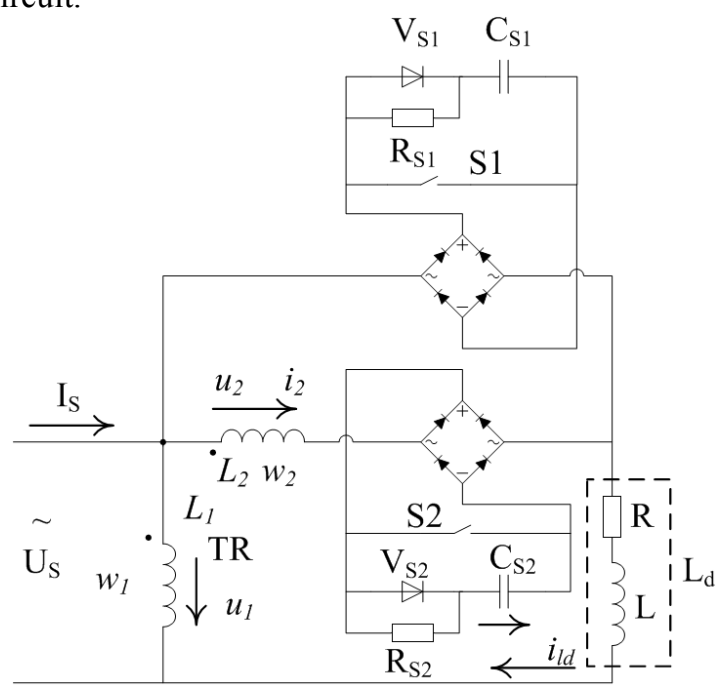

Fig. 1. Scheme of the transformer based AC modulation system accepted for investigations. 
Effective voltage of winding $w_{2}$ is $\mathrm{U}_{2}=\mathrm{U}_{\mathrm{s}} \mathrm{w}_{2} / \mathrm{w}_{1}=\mathrm{U}_{\mathrm{s}} / \mathrm{N}$ and transformation ratio $\mathrm{N}$ is approximately 10 , which would ensure compensation of $\mathrm{U}_{\mathrm{S}}$ rise on the load.

When voltage on the load is lower than needed, switch S2 is turned off and switch S1 - turned on. Switching process is implemented with constant and high enough frequency $f_{m}$, as well is controlled a switching duty ratio of switches S1 and S2 in constant switching cycle $T_{m}$ to achieve necessary output RMS voltage. If on-duty cycle for switch S1 is accepted as $D=t_{1} \cdot f_{m}$, than simplified load voltage and network current waves in a k-th modulation interval can be shown as in Fig.2.

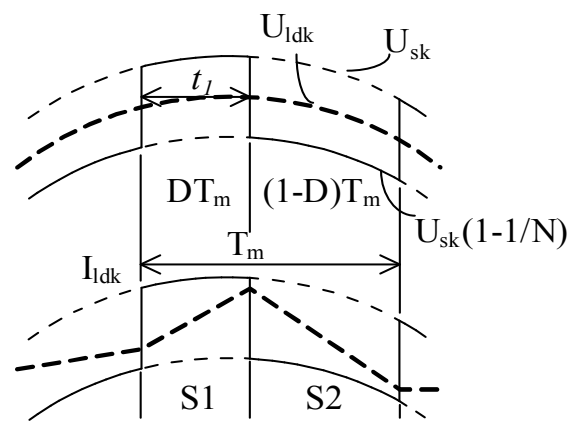

Fig. 2. Simplified diagrams of load voltage and supply current in one $(k)$ switching cycle

Simplified average voltage of the load at $\mathrm{k}$-th interval is:

$$
U_{l d k}=U_{s k} D+(1-D) U_{s k}\left(\frac{N-1}{N}\right)=U_{s k}\left(\frac{N-1+D}{N}\right) .
$$

Simplified source current value in k-th interval is:

$$
I_{s k}=I_{l d k} D+I_{l d k}\left(1-\frac{1}{N}\right)(1-D)=I_{l d k}\left(\frac{N-1+D}{N}\right) .
$$

Here $U_{s k}$ is averaged meaning of supply voltage wave in the $\mathrm{k}$-th modulation interval, $\mathrm{I}_{\mathrm{ldk}}$ - same for load current wave.

\section{SWITCHING PROCESSES AND ITS INFLUENCE ON OUTPUT PARAMETERS}

Let's consider switching process from the on-position of the switch S2 to the on-position of the switch S1 (see Fig.3). At the moment when the switch $\mathrm{S} 1$ is turned-on and the switch S2 - turned-off, the transient process starts. Through the snubber capacitor $\mathrm{C}_{\mathrm{s} 2}$ of the switch $\mathrm{S} 2$ current $\mathrm{i}_{2}$ of the winding $\mathrm{w}_{2}$ of transformer passes and instantaneous meanings of current through the $\mathrm{S} 1$ in the very-short k-interval of supply voltage (modulation interval) wave can be find as difference of constant meaning of load current $\mathrm{I}_{\mathrm{ldk}}$ and decreasing to zero in the transient process current $i_{2}$. Duration of the process is accepted as $t_{k}$ and at its end current of the switch $\mathrm{S} 1$ becomes equal to the $\mathrm{I}_{\mathrm{ldk}}$ and voltage of snubber capacitor $\mathrm{C}_{\mathrm{s} 2}$ - its maximum value for the $\mathrm{k}$-th interval $\mathrm{U}_{\mathrm{C} 2 \mathrm{~km}}$. Process depends on angular speed $\omega=\left(\mathrm{L}_{2 \mathrm{TR}} \cdot \mathrm{C}_{\mathrm{s}}\right)^{-0.5}$ and wave impedance $\rho=\left(\mathrm{L}_{2 \mathrm{TR}} / \mathrm{C}_{\mathrm{s}}\right)^{0.5}$, where it's accepted that the both snubber capacitors are equally by its volume (i.e. to $\mathrm{C}_{\mathrm{s}}$ ). Here $\mathrm{L}_{2 \mathrm{TR}}$ is a total leakage inductance of transformer reduced to the secondary winding $\mathrm{w}_{2}: \mathrm{L}_{2 \mathrm{TR}}=$ $=\mathrm{L}_{2}+\mathrm{L}_{1}$.

The process can be described with expressions as follows: differential equation regard to the current $i_{2}$

$$
-U_{2 k}=L_{2 T R} \frac{d i_{2 k}}{d t}+\frac{1}{C_{s 2}} \int i_{2 k} d t \quad ;
$$

expression for the current $\mathrm{i}_{2}$ change in the transient process

$$
i_{2 k}=-\frac{U_{2 k}}{\omega L_{2 T R}} \sin \omega t+I_{l d k} \cos \omega t
$$

expression for the current $\mathrm{i}_{1}$ of switch $\mathrm{S} 1$ rise

$$
i_{1 k}=\frac{U_{2 k}}{\omega L_{2 T R}} \sin \omega t+I_{l d k}(1-\cos \omega t) .
$$

expression for calculation of duration of the transient process

$$
t_{k}=\frac{1}{\omega} \operatorname{arctg} \frac{I_{l d k} \omega L_{2 T R}}{U_{2 k}} ;
$$

expression for calculation of the end value of snubber capacitor value in the process

$$
U_{C 2 k m}=\frac{U_{2 k}^{2}-U_{2 k} \sqrt{U_{2 k}^{2}+I_{l d k}^{2} \rho^{2}}+I_{l d k}^{2} \rho^{2}}{\sqrt{U_{2 k}^{2}+I_{l d k}^{2} \rho^{2}}} .
$$

If at constant $U_{2 k}$ and $\rho$ a relative meaning of load current $\mathrm{I}_{\mathrm{ldk}}{ }^{*}=\mathrm{I}_{\mathrm{ldk}} \cdot \rho / \mathrm{U}_{2 \mathrm{k}}$ is applied then a relative meaning of capacitor $C_{2}$ voltage amplitude in respect to the $U_{2 k}$ can be described as

$$
U_{C 2 k m}^{*}=\sqrt{1+I_{l d k}^{* 2}}-1
$$

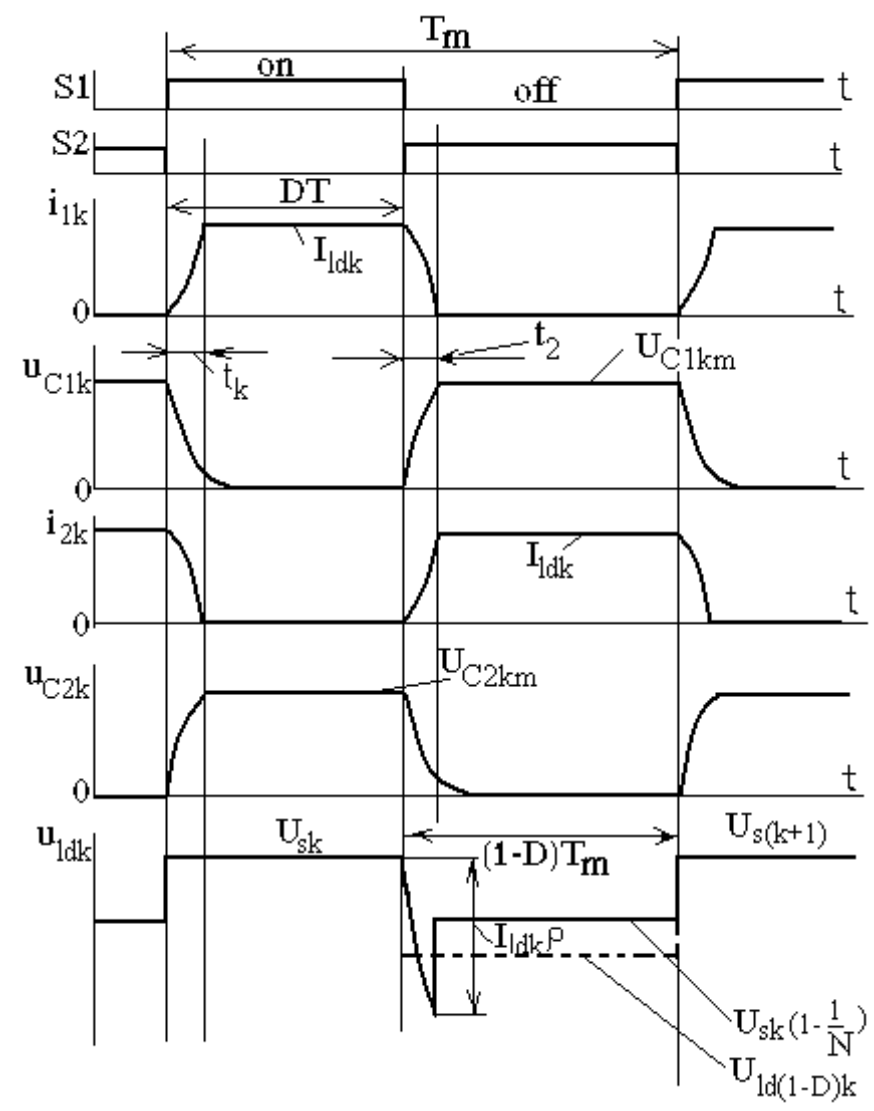

Fig.3. Diagrams of signals in the k-interval of network voltage wave

When the switch S2 is turned-on but S1 - turned-off, then rise of current through switch $\mathrm{S} 2$ and current $\mathrm{i}_{2 \mathrm{k}}$ of transformer's winding $\mathrm{w}_{2}$ starts but in the way of transient a balance of currents, similar as in the first case, is in force.

Rise speed of current of the secondary winding in the transient interval depends on variations of voltage of the 
snubber capacitor $\mathrm{C}_{\mathrm{S} 1}$ of the switch $\mathrm{S} 1$ which should be described as

$$
\frac{1}{C_{S}} \int i_{1 k} d t-L_{2 T R} \frac{d i_{2}}{d t}-U_{2 k}=0
$$

As result at constant in the k-th interval load current, current of switch $\mathrm{S} 1$ is changing as

$$
i_{1 k}=U_{2 k} \sin \omega t+I_{l d k} \cos \omega t
$$

but current of winding $\mathrm{w}_{2}-$ as

$$
i_{2 k}=I_{l d k}(1-\cos \omega t)-\frac{U_{2 k}}{\rho} \sin \omega t \text {. }
$$

The process ends when $i_{2 k}=I_{1 d k}$ and then length of the process can be find from expression

$$
\operatorname{tg} \omega t_{2}=-\frac{\rho I_{l d k}}{U_{2 k}}
$$

and taking into account that the angle is bigger as $\pi / 2$, time interval can be calculate as

$$
t_{2}=\frac{1}{\omega}\left[\pi+\operatorname{arctg}\left(-\frac{\rho I_{l d k}}{U_{2 k}}\right)\right] .
$$

Voltage of snubber capacitor $C_{1 \mathrm{~s}}$ in the process changes as

$$
u_{C 1 k}=-U_{2 k} \cos \omega t+I_{l d k} \rho \sin \omega t+A
$$

from where taking into account the initial value of the voltage $\mathrm{u}_{\mathrm{C} 1 \mathrm{k} 0}=0$, the constant $\mathrm{A}=\mathrm{U}_{2 \mathrm{k}}$. Then voltage of the capacitor $\mathrm{C}_{1 \mathrm{~s}}$ changes as

$$
u_{C 1 k}=U_{2 k}(1-\cos \omega t)+I_{l d k} \rho \sin \omega t \text {. }
$$

reaching its end value $U_{\mathrm{Clkm}}$ at time instant when current $i_{1 \mathrm{k}}=0$ but current $i_{2 \mathrm{k}}$ reaches its maximum value $\mathrm{I}_{\mathrm{ldk}}$ (see Fig.3). This maximum value can be calculate as

$$
U_{C 1 k m}=\frac{U_{2 k}^{2}+U_{2 k} \sqrt{U_{2 k}^{2}+I_{l d k}^{2} \rho^{2}}+I_{l d k}^{2} \rho^{2}}{\sqrt{U_{2 k}^{2}+I_{l d k}^{2} \rho^{2}}}
$$

If at constant $U_{2 k}$ and $\rho$ a relative meaning of load current $\mathrm{I}_{\mathrm{ldk}}{ }^{*}=\mathrm{I}_{\mathrm{ldk}} \cdot \rho / \mathrm{U}_{2 \mathrm{k}}$ is applied then a relative meaning of capacitor $\mathrm{C}_{1}$ voltage amplitude in respect to the $\mathrm{U}_{2 \mathrm{k}}$ can be described as

$$
U_{C 1 k m}^{*}=1+\sqrt{1+I_{l d k}^{* 2}} .
$$

It must be accounted that here as basic units the meanings of $\mathrm{U}_{2 \mathrm{k}}$ and $\mathrm{I}_{2 \mathrm{k}}$ are used which really represent an amplitude (peak) meanings of the secondary voltage $U_{2}$ and secondary current $\mathrm{I}_{2}$ of transformer.

Using expressions (8) and (16) in Fig.4 the relative to the amplitude of voltage of secondary winding of transformer a values of an amplitudes of voltage of the both snubber capacitors versus relative load current in the k-th interval of modulation are presented. As it can be seen at rise of loading rate the amplitudes of voltages across the both snubber capacitors are rising too. At that at same loading rate if capacitances of the both snubber capacitors are equal voltage amplitudes for snubber capacitor of switch S2 are smaller as for snubber capacitor of switch S1.

Obtained expressions should be applied for proper choice of snubber capacitors in dependence as on value of $U_{2 k}$ as well on leakage inductance of transformer. For instance, if the rated power of transformer is $50 \mathrm{VA}$, load current at its peak is $3.2 \mathrm{~A}$, summary leakage inductance of transformer respected to the secondary winding $\mathrm{L}_{2 \mathrm{TR}}=4.32 \mathrm{mH}$, but windings ratio is 8.33 (i.e. $\mathrm{U}_{2 \mathrm{k}}$ can reach $40.8 \mathrm{~V}$ at amplitude of supply voltage $340 \mathrm{~V}$ ) then for $\mathrm{U}_{\mathrm{C} 1 \mathrm{~km}}{ }^{*}=10$ necessary to obtain loading ratio 9.94 and wave impedance $\rho=114$. At that necessary capacitance for snubber of switch $\mathrm{S} 1$ is $0.33 \mu \mathrm{F}$.

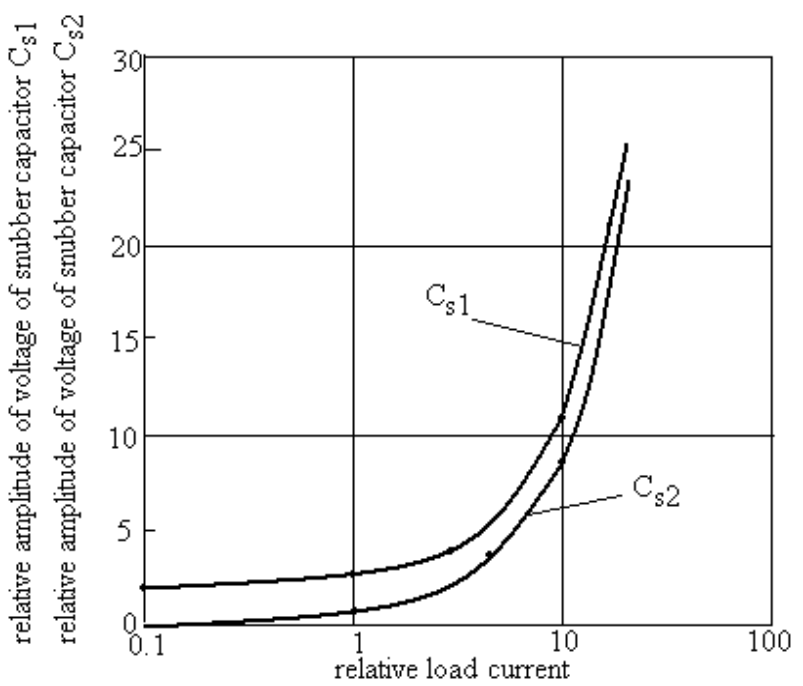

Fig.4. Dependence curves of snubber capacitors voltage amplitudes relative to the voltage of secondary winding on relative loading rate

Rise of current in the winding $\mathrm{w}_{2}$ at turn-on of the switch $\mathrm{S} 2$ is connected with self-inductance voltage generation in the inductance $\mathrm{L}_{2 \mathrm{TR}}$. As result load voltage can be decreased by this generated voltage in way of the transient process and this process can be described with equation

$$
\begin{aligned}
& u_{l d k}=U_{s k}\left(1-\frac{1}{N}\right)-L_{2 T R} \frac{d i_{2 k}}{d t}= \\
& =U_{s k}\left(1-\frac{1}{N}\right)-\rho I_{l d k} \sin \omega t+U_{2 k} \cos \omega t
\end{aligned}
$$

where time interval is from 0 to the $t_{2}$. At that it can be accepted that largest instantaneous decrease of voltage is at instant, when $\omega_{k} t=0.5 \pi$ (see Fig. 3 ). As result really realized load voltage in the time interval (1-D)T is less as $U_{s k}\left(1-\frac{1}{N}\right)$ and should be approximately considered with expression

$$
u_{l d(1-D) k}=U_{s k}\left(1-\frac{1}{N}\right)-I_{l d k} \rho_{k} \frac{\pi \cdot f_{m}}{2 \omega_{k}(1-D)}
$$

Taking into account decreasing of voltage in the intervals (1-D)T and as well phase shift of the fundamental harmonic of load current $\varphi=\operatorname{arctg} \frac{\omega_{S} L_{l d}}{R_{l d}}$ in respect to the load voltage wave, where $R_{l d}$ and $L_{l d}$ are respectively resistance and inductance of load, a wave of the fundamental of load voltage can be described with expression 
$u_{l d(1)}=U_{s m}\left(\frac{N-1+D}{N}\right)\left[\sin \omega_{s} t-\frac{\rho_{k} \pi f_{m}}{z_{l d} 2 \omega_{k}} \sin \left(\omega_{s} t-\varphi\right)\right]$

where $\mathrm{U}_{\mathrm{sm}}$ is the amplitude of supply voltage, $\omega_{S}$ is an angular speed for supply voltage wave, $z_{\mathrm{ld}}$ is an impedance of the load.

As it can be seen a wave of load voltage is performed by two rotating phasors shifted by angle $\varphi$ and the common phasor of load voltage can be obtained using subtraction of the second phasor dependant on the load current from the main phasor performed by modulation. At such approach the modulus of the common load voltage phasor is

$$
U_{l d(1) m}=U_{s m}\left(1-\frac{1}{N}\right) \sqrt{1-\frac{\rho_{k} \pi f_{m}}{z_{l d} \omega_{k}}+\left(\frac{\rho_{k} \pi f_{m}}{2 z_{l d} \omega_{k}}\right)^{2}},
$$

and angle $\delta$ by which the fundamental of load voltage leads regard to the supply one - as

$$
\delta=\operatorname{arctg}\left(\frac{\rho_{k} \pi f_{m} \sin \varphi}{\left(2 z_{l d} \omega_{k}-\rho_{k} \pi f_{m} \cos \varphi\right.}\right)
$$

\section{IV.ESTIMATION OF SNUBBER CAPACITOR VALUES}

Taking into account impedance voltage of transformer the respected to the secondary side leakage inductance of transformer should be presented as

$$
L_{2 T R}=\frac{0.09 U_{1 N}^{2}}{S_{T N} \omega N^{2}}
$$

where the impedance voltage is accepted as $0.09, \mathrm{~S}_{\mathrm{TN}}$ is rated power of transformer but $U_{1 N}$ is its rates voltage of primary winding.

Then from expression (16) necessary value of snubber capacitor should be calculate as

$$
C_{S}=\frac{0.09 S_{T N} N^{2}}{U_{1 N}^{2} \omega\left[\left(\frac{N U_{C 1 \max }}{\sqrt{2} U_{1 N}}-1\right)^{2}-1\right]}
$$

It's seen that necessary capacitance is directly proportional to the rated power of transformer and more complex - to the applied value of windings ratio $\mathrm{N}$ which characterize loading capacity of the system - this factor can be presented as

\section{$\mathrm{k}_{\mathrm{ld}}=\mathrm{N}-1$.}

In Fig. 5 there are presented dependence of calculated by (23) values of necessary capacitance of snubber capacitor $\mathrm{C}_{\mathrm{s} 1}$ at rated power of transformer $50 \mathrm{VA}, \mathrm{U}_{1 \mathrm{~N}}=230 \mathrm{~V}, \omega=314$ $1 / \mathrm{s}$ and some values of relation between $U_{\mathrm{C} 1 \max }$ and $U_{1 \mathrm{~N}}$ on windings ratio $\mathrm{N}$.

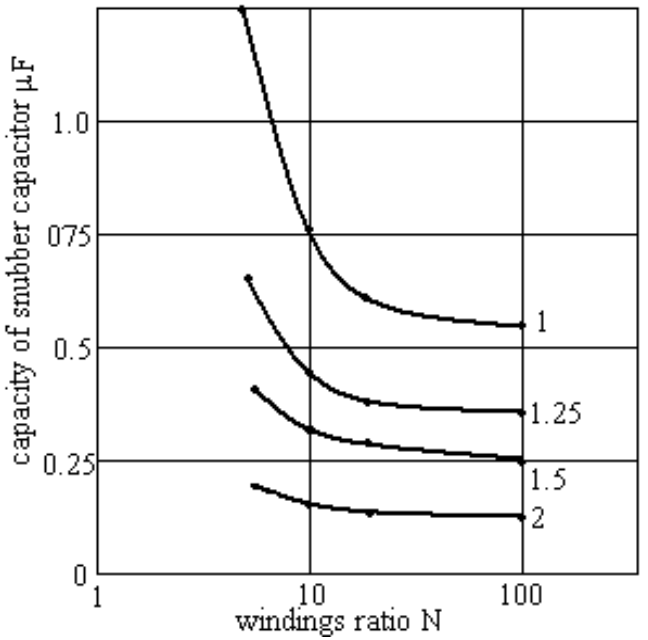

Fig.5. Dependence of capacitance of snubber capacitor on windings ratio $\mathrm{N}$ at some values of relation of capacitor voltage amplitude to rated supply voltage

As it can be seen at application of bigger values of winding ratio and bigger values of load current too, when load power can be set at large values regard to rated power of transformer, a capacitance of snubber capacitor should be decreased. It's connected at that with decreasing of leakage inductance of transformer.

\section{VERIFICATION OF SWITCHING PROCESSES AND ITS INFLUENCE ON OUTPUT PARAMETERS}

For verification of processes a computer modelling have been done applying transformer of 50VA, winding's ratio $\mathrm{w}_{1} / \mathrm{w}_{2}=8.33$, reduced to the secondary winding leakage inductance $\mathrm{L}_{2}=\mathrm{L}_{1}=2.16 \mathrm{mH}$, resistance of windings $\mathrm{R}_{2}=\mathrm{R}_{1}{ }^{\prime}=0.137 \Omega$, magnetizing inductance $\mathrm{L}_{\mathrm{m}}=30 \mathrm{H}$ with load as $\mathrm{R}=100 \Omega, \mathrm{L}=50 \mathrm{mH}$ and transistor pulse modulator operating with modulation frequency $\mathrm{f}_{\mathrm{m}}=1 \mathrm{kHz}$ at different duty ratios. In the table 1 some calculation results of process parameters for $\mathrm{U}_{\mathrm{sm}}=340 \mathrm{~V}, 50 \mathrm{~Hz}$ at applied duty ratio $\mathrm{D}=0.7$ of modulator with RDC snubbers comprising $\mathrm{C}_{\mathrm{s}}=1 \mu \mathrm{F}$ and $\mathrm{R}_{\mathrm{s}}=50 \Omega$ as well obtained ones from computer modelling are presented.

TABLE I

CALCULATED AND SIMULATED PARAMETERS

\begin{tabular}{|c|c|c|}
\hline $\begin{array}{c}\text { Name of the operating } \\
\text { parameter }\end{array}$ & $\begin{array}{c}\text { Calculated } \\
\text { value }\end{array}$ & $\begin{array}{c}\text { Simulated } \\
\text { value }\end{array}$ \\
\hline RMS voltage of the load & $229.4 \mathrm{~V}$ & $226.0 \mathrm{~V}$ \\
\hline $\begin{array}{c}\text { Amplitude of load } \\
\text { current }\end{array}$ & $3.21 \mathrm{~A}$ & $3.09 \mathrm{~A}$ \\
\hline RMS of load current & $2.26 \mathrm{~A}$ & $2.2 \mathrm{~A}$ \\
\hline RMS of supply current & $96.1 \mathrm{~V}$ & $2.14 \mathrm{~A}$ \\
\hline $\begin{array}{c}\text { Load voltage drop at } \\
\text { turn-on of S2 }\end{array}$ & $1.52 .10^{4} 1 / \mathrm{s}$ & $\mathrm{V}$ \\
\hline $\begin{array}{c}\text { Angular speed for } \\
\text { snubber circuits }\end{array}$ & $9.10^{-5} \mathrm{~s}$ & $8.8 .10^{-5} \mathrm{~s}$ \\
\hline $\begin{array}{c}\text { turn-on transient interval } \\
\text { of S1 }\end{array}$ & $166 \mathrm{~V}$ & $154.9 \mathrm{~V}$ \\
\hline $\begin{array}{c}\text { S2 snubber capacitor } \\
\text { maximal voltage }\end{array}$ & $1.15 .10^{-4} \mathrm{~s}$ & $1.04 .10^{-4} \mathrm{~s}$ \\
\hline $\begin{array}{c}\text { S2 turn-on transient } \\
\text { interval }\end{array}$ & $254.0 \mathrm{~V}$ & $245.8 \mathrm{~V}$ \\
\hline $\begin{array}{c}\text { S1 snubber capacitor } \\
\text { maximal voltage }\end{array}$ & & \\
\hline \multicolumn{2}{|c|}{} & \\
\hline
\end{tabular}


As it can be seen a compliance of the calculated and simulated parameters is rather good. Simulated diagrams of currents of switches and voltages of snubber capacitor at above mentioned parameters are presented in Fig.4 but diagrams of source and load voltages as well its currents are presented in Fig.5.

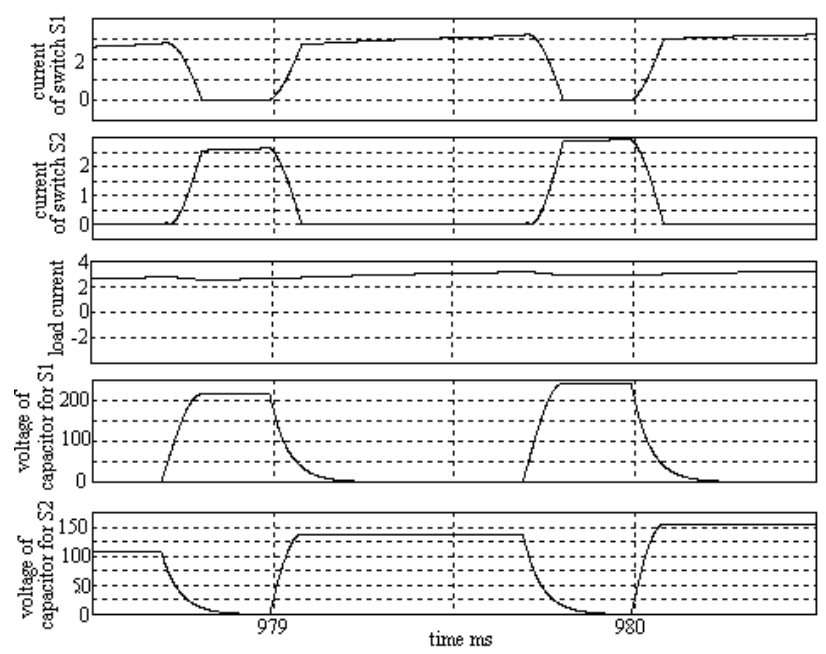

Fig.4. Simulated diagrams of processes in the circuits of switches of Transformer based AC modulated system at accepted parameters
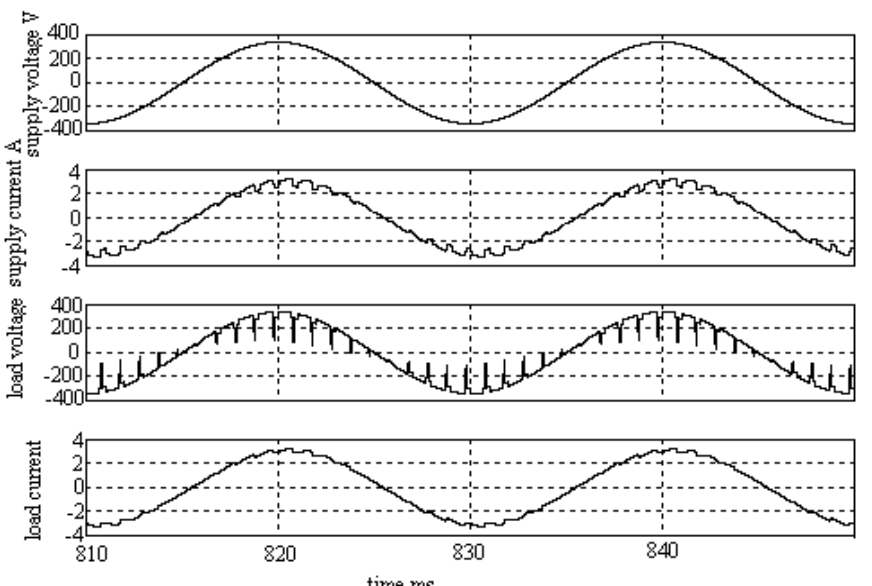

Fig.5. Simulated diagrams of source and load voltage and its currents at parameters mentioned in the text

In Fig.6 are diagrams obtained at experimental system model device in approximate $0.7 \mathrm{~kW}$ operation regime on the load. The $\mathrm{R}_{\mathrm{ld}}=69 \Omega$. Snubber capacitors are applied at volume only $0.22 \mu \mathrm{F}$, but duty ratio is accepted 0.5 . Other parameters correspond to the previous mentioned for simulation case.

Measured source current and voltage is shown on Fig.7. And it can be seen that it is just as expected.

As it can be seen the wave of load voltage comprises two meanings - voltage of supply and lowered by voltage of secondary winding one, and as result RMS value of load voltage is lowered to $220 \mathrm{~V}$. Because load is clean active one the ripples of voltage wave effect the wave of load current which is rippling too.

Snubber capacitor voltage diagrams approve that $0.22 \mu \mathrm{F}$ is sufficient for operation with effective load current of about 3.10A. Snubber capacitor size can be reduced for this operation regime with no damage to system elements. But for correct snubber capacitor choice more investigations regard to the problem must be done for farther developing of devices at different rate of power.
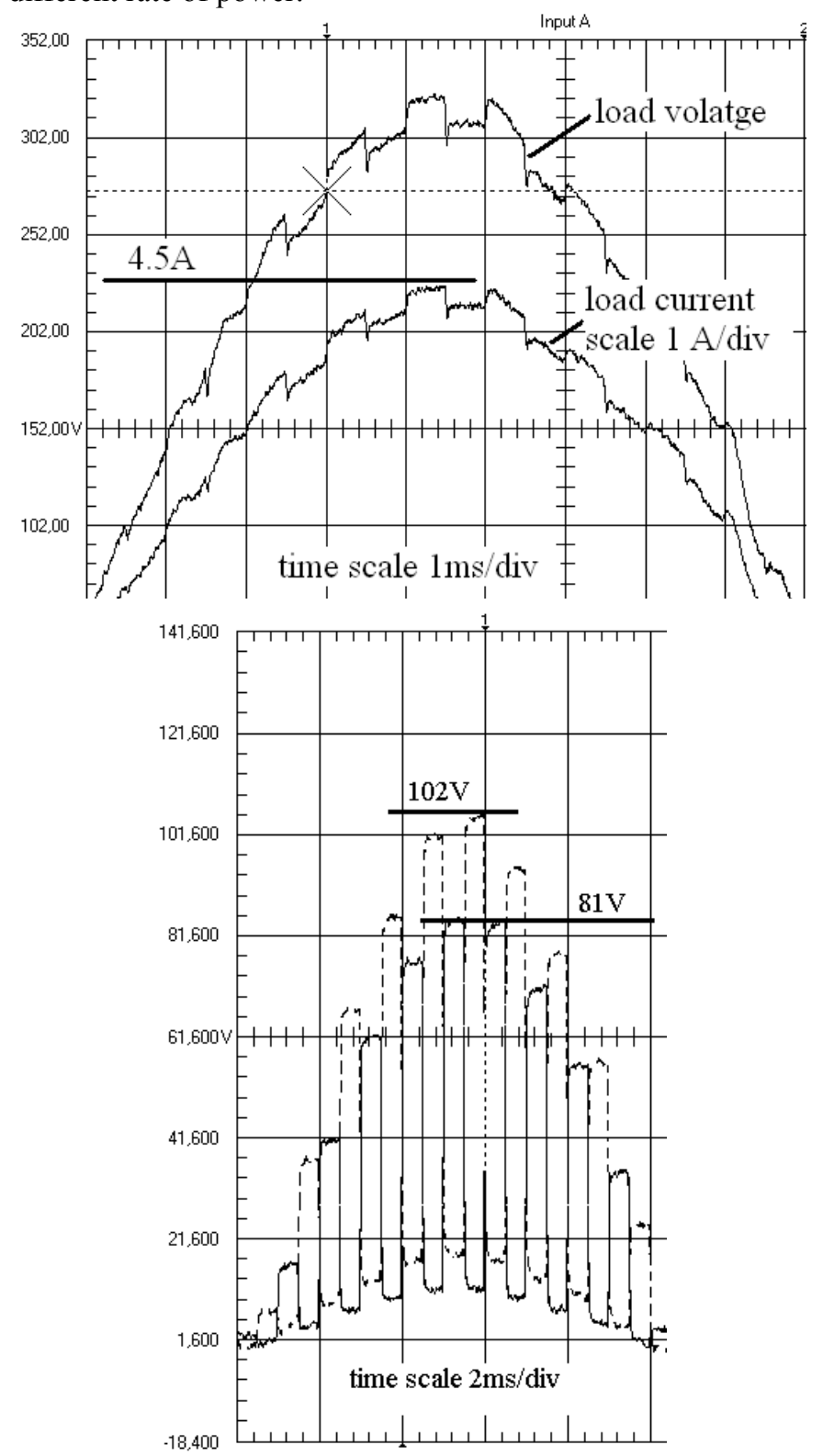

$401 \mathrm{~ms}$

Fig.6. Experimental obtained diagrams of load voltage and its current (above) and diagrams of currents in the circuits of the both switches.

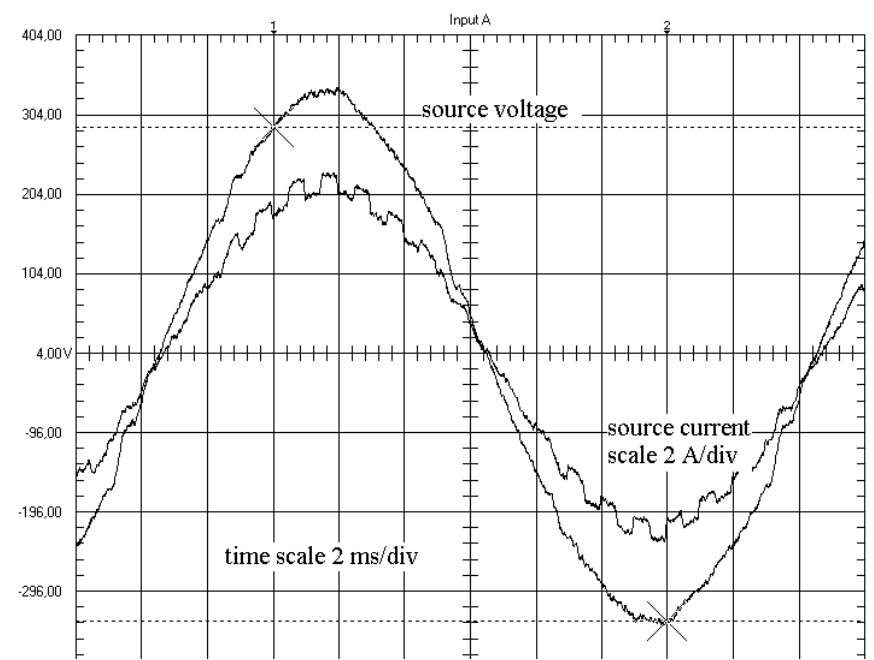

Fig.7. Experimental obtained diagrams of source voltage and its current. 
From the first view a leakage inductance of transformer windings at constant impedance voltage indicator is at reverse dependence on rated power of transformer. Therefore keeping relation $\mathrm{I}_{1 \mathrm{~d}} \cdot \mathrm{L}_{2 \mathrm{TR}} / \mathrm{C}_{\mathrm{s}}$ as constant a choice of snubber capacitor volume should be directly proportional to the square root of transformer power rate.

In the experiment done RMS value of source voltage was approximately $240 \mathrm{~V}$, but RMS value on load was $220 \mathrm{~V}$. Input and output current stayed the same - about 3 A. This means that about $60 \mathrm{~W}$ were turned to heat. So efficiency of test circuit is about $92 \%$.

\section{CONCLUSIONS}

1. The device can operate as stabilizer of load voltage below the level of supply network one with possibility to fluently change RMS value of voltage.

2. Switching processes in large extent depend on parameters of snubber circuits for transistor switches.

3. Calculation of switching processes can be done using obtained expressions which comply well with results of simulations and experiments.

4. Parameters of snubber capacitors applied depend on load power but the subject must be investigate more properly.
This work has been supported by Latvian National Research Programme "LATENERGI".

\section{REFERENCES}

[1] LVS EN 50160:2010 (standard) "Voltage characteristics of the Public Electric Supply Networks" (in Latvian)

[2] LV patent Nr.13835 B "Stabilizer of a single-phase AC voltage". V.Hramcovs, I.Rankis, V.Cimanis. 2008

[3] V.Cimanis,V.Hramcovs, I.Rankis The single-phase AC regulator on base of bidirectional IGBT switches. - Proc. of 9th Internat. Symp."Top.Problem in the field of El. and Pow.Eng.", 2010, Parnu, Estonia. - pp.12-15

[4] LV patent Nr.13895 B ,Sensor of the amplitude of AC sinus shape voltage. V.Hramcovs, I.Rankis, V.Cimanis. 2008

[5] V.Cimanis, V.Hramcovs, I.Rankis Investigation of the operation speed of AC voltage sensor. - Proc. Of Intern. Conf., Narva-Joesuu, Estonia. 2009. - pp 89-92

[6] Cimanis V., Hramcovs V., Rankis I. The single-phase AC regulator on base of bidirectional IGBT switches. Proc. of 51st Ann. Intern. Sc. Conf. of RTU, Pow.and El.Eng., Riga:RTU, 2010, pp.195-198

[7] Rankis I., Vasilevics O. Estimation of Parameters of Network Filter for AC Pulse Regulator. Power and Electrical Engineering, N31, 2013 Riga:RTU, pp.91-94

[8] T. Wildi Electrical Machines, Drives, and Power Systems, New Jersey, USA, 2002, 886p

[9] Shirkin D., Rankis I. Transformer Based AC Pulse Regulation Systems. Proc. Of $55^{\text {th }}$ Int. Sc. Conf. on Pow. And Electr. Eng. RTUCON, 2014. - pp.52-55

[10] F. L. Zalamanovich, "Multistage AC voltage stabilizer".Russian Federation Patent 2237270/G05F1/30,H02M5/12, September 27, 2004

[11] E. P. Trabach, "A stabilized single phase electronic autotransformer" Industrial Electronics Society, 1999. IECON '99 Proceedings. The 25th Annual Conference of the IEEE. Vol. 1. pp. 222-227. November 1999. 